\title{
BMJ Open Prevalence and types of sexual inactivity in Britain: analyses of national cross- sectional probability survey data
}

\author{
Peter Ueda (D) ,1,2 Catherine $\mathrm{H}$ Mercer $^{3}$
}

\begin{abstract}
To cite: Ueda P, Mercer $\mathrm{CH}$. Prevalence and types of sexual inactivity in Britain: analyses of national cross-sectional probability survey data. BMJ Open 2019;9:e030708. doi:10.1136/ bmjopen-2019-030708
\end{abstract}

- Prepublication history and additional material for this paper are available online. To view these files, please visit the journal online (http://dx.doi. org/10.1136/bmjopen-2019030708).

Received 27 March 2019 Revised 30 August 2019 Accepted 17 September 2019

Check for updates

(C) Author(s) (or their employer(s)) 2019. Re-use permitted under CC BY-NC. No commercial re-use. See rights and permissions. Published by BMJ.

${ }^{1}$ Clinical Epidemiology Division, Department of Medicine, Solna, Karolinska Institute, Stockholm, Sweden

${ }^{2}$ Graduate School of Medicine, Department of Global Health Policy, University of Tokyo,

Bunkyo-ku, Japan

${ }^{3}$ Centre for Population Research in Sexual Health and HIV, Institute for Global Health, University College London, London, UK

Correspondence to

Dr Peter Ueda; peter.ueda@ki.se

\section{ABSTRACT}

Objectives To examine how prevalence and context of sexual inactivity varies across the life-course, assess dissatisfaction with sex life among those who are sexually inactive and identify associations with factors that may represent reasons for sexual inactivity.

Design Analysis of cross-sectional probability sample survey data.

Setting British general population.

Participants 14623 participants (n men: 6045 unweighted, 7245 weighted), aged 16-74 years, of the third National Survey of Sexual Attitudes and Lifestyles (Natsal-3), undertaken in 2010-2012.

Main outcome measures Sexual inactivity, defined as not reporting oral, vaginal or anal intercourse in the past year and further categorised into those who were sexually inexperienced (had never had sex), single or in a relationship.

Results Overall, $15.9 \%$ (weighted $n$ 1155/7245) of men and $22.2 \%(1646 / 7410)$ of women were sexually inactive $(p<0.001)$. The proportion of sexually inactive individuals who were sexually inexperienced was larger among men than women (26.3\% (304/1155) vs $16.3 \%$ (268/1646)), while the proportion who were singles was larger among women $(49.8 \%(820 / 1646)$ vs $40.4 \%(467 / 1155))$. Sexual inexperience was the most common type of sexual inactivity in early adulthood, with this declining with age. A minority of those who had sexual experience but were sexually inactive-34.8\% (293/842) of men and $23.6 \%$ (319/1349) of women-reported being dissatisfied with their sex lives. Associations with sexual inactivity was observed for a range of sociodemographics and sexual behaviours/attitudes, for example, religion, ethnicity, Body mass index, height, employment status and index of multiple deprivation; these associations varied by type of sexual inactivity and gender.

Conclusions While sex is important for well-being, a non-negligible proportion of the population at all ages are sexually inactive, yet many are not dissatisfied with their situation, with implications for sex and relationship counselling.

Sexual health and satisfaction are key components of health and well-being. ${ }^{1-3}$ Happiness and life satisfaction can be positively influenced by sexual relationships ${ }^{4-6}$ while low sexual frequency has been shown to be associated with poor self-reported health ${ }^{7}$ and

\section{Strengths and limitations of this study}

In this study of sexual inactivity and its association with sociodemographic and sexual behaviours/attitudes, we included men and women across a wide age-range, corresponding to most of adulthood, using nationally representative data from Britain.

- Although the sample was weighted to be broadly representative of the underlying British population, non-response could be a source of bias for our data.

- Due to the cross-sectional design, temporality of the associations between participant characteristics and sexual inactivity could not be determined.

- In some of the analyses of different types of sexual inactivity, statistical power was limited.

increased mortality. ${ }^{8}$ While the importance of sex for quality of life has been increasingly recognised, ${ }^{1-3}$ surprisingly little is known about those in the population that are sexually inactive.

In Britain's third National Survey of Sexual Attitudes and Lifestyles (Natsal-3), around one in five men and women aged $16-74$ years reported that they had not had any sexual partners in past year. ${ }^{9}$ While this measure of sexual inactivity was more common in the oldest age groups, one in four to one in five of men and women aged 16-24 years and around 1 in 10 of those aged 25-34 years reported being sexually inactive. ${ }^{9}$ The sexually inactive proportion of the population has remained stable in Britain between 1991 and 2011. ${ }^{9}$ A study using a nationally representative data from the USA, however, showed that $15 \%$ of those aged $20-24$ years who were born in the 1990s had had no sexual partners since age 18 years, compared with $6 \%$ in the same age-range of those born in the $1960 \mathrm{~s} .{ }^{10}$ Similarly, the proportion of German men aged 18-30 years that reported no sexual activity in the past 12 months increased from $7.5 \%$ in 2005 to $20.3 \%$ in $2016 .{ }^{11}$

Important knowledge gaps regarding sexual inactivity remain. Little is known about the reasons for being sexually inactive. ${ }^{12}{ }^{13}$ Some 
individuals may choose to remain sexually inactive due to reasons such as religion or low or no sexual desire. ${ }^{1415}$ Conversely, access to potential sexual partners and the individual's ability to pursue sexual relationships may also affect the likelihood of being sexually inactive. ${ }^{12}$ Previous studies, which have assessed sexually inactive individuals as one group, ${ }^{916}$ or investigated only one type of sexual inactivity (eg, those with no sexual experience or those in sexless relationships), ${ }^{10}$ 17-19 indicate that reasons for being sexually inactive might differ by type of sexual inactivity. ${ }^{12-15} 17-19$

In this study, we assessed the proportion of adults in Natsal-3 who had no experience of sex, were sexually inactive singles and sexually inactive while in a relationship $^{12-1517-19}$ and how this varied by gender and age-group. Next, we assessed the proportion of the sexually inactive individuals who were dissatisfied with their (lack of) sex life and who avoided sex due to sexual difficulties, and identified factors associated with sexual inactivity that could be related to potential reasons for being sexually inactive.

\section{METHODS}

\section{Data sources}

The Natsal surveys are decennial national probability sample surveys on sexual health and behaviour in Britain. We used data from Natsal-3 (2010-2012); detailed information about the survey has been provided elsewhere. ${ }^{90}$ In brief, a multistage, clustered and stratified probability sample design was applied using postcode sectors as the primary sampling units. Within each primary sampling unit, addresses were randomly selected from which one individual was invited to participate in the survey. Survey participants then completed the survey, usually in their homes, through a combination of face-to-face interviews using computer-assisted personal interview with computer-assisted self-interview. The estimated response rate was $57.7 \%,{ }^{9}$ and the number of interviews that were completed after contact was made was $65.6 \%$ (the estimated cooperation rate). ${ }^{21}$ Sample weights were derived to adjust for unequal probabilities of selection and non-response; after application of sample weights, the samples were broadly representative of the British population in 2011.

\section{Study population}

All of the 15162 participants in Natsal-3 were eligible for this analysis. We excluded those with missing data on variables required to define or categorise sexual inactivity (see online supplementary material), including information about having had oral, anal or vaginal intercourse in the past year $(n=38)$, relationship status at interview $(n=296)$ and/or previous sexual experience $(n=294)$. The final study population included 14623 survey participants. The characteristics of excluded participants and the study population are shown in online supplementary table 1 . Those who were excluded differed with respect to several characteristics as compared with the study population. For example, they were more likely to be aged $65-74$ years, to be unemployed and to have missing information on other variables (online supplementary table 1).

\section{Categories of sexual inactivity, satisfaction with sex life and} avoidance of sex due to sexual difficulties

Participants who reported no partnered sexual activity, specifically vaginal, anal or oral sex, in the past year were considered sexually inactive and were further categorised into one of three groups: (1) sexually inexperienced (those who reported that they had never had sexual intercourse); then among those who reported ever having had sexual intercourse: (2) sexually inactive but in a relationship at interview (those who were married or cohabitating with a partner or had a steady relationship but were not living together with their partner); (3) sexually inactive single (those who were not in a relationship at interview as defined above).

Participants in Natsal-3 who indicated that they strongly disagreed or disagreed with the statement 'I am satisfied with my sex life' were considered as dissatisfied. We also assessed avoidance of sex due to sexual difficulties, which was defined as strongly agreeing or agreeing with the statement 'I have avoided sex because of sexual difficulties, either my own or those of my partner'. The questions regarding satisfaction with sex life and avoidance of sex were not asked to those who reported no sexual experience.

\section{Factors for assessment of association with sexual inactivity}

We selected (a priori) variables that we hypothesised could be associated with reasons for sexual inactivity, including religion $^{17}$ (none; Christian; other religions), sexual attraction $^{14}$ (have felt sexual attraction; never felt sexual attraction to anyone), masturbation in the past week (yes; no), lifetime sexual partners ( $0 ; 1 ; 2$ to $4 ; 5$ or more) and ever paid for sex (yes; no). Due to their demonstrated relationship with sexual activity or associated factors, we assessed socioeconomic factors ${ }^{162-25}$ including education (no academic qualifications; academic qualifications typically gained at age 16 years; studying for or have attained further academic qualifications), National Statistics Socio Economic Classification (NSSEC) ${ }^{26}$ (managerial and professional occupations; intermediate occupations; semiroutine and routine occupations; never worked and long-term unemployed; full-time student) and quintile of Index of Multiple Deprivation, ${ }^{27}$ as well as physical characteristics, ${ }^{1728-30}$ including body mass index (underweight or normal weight $\left(<25 \mathrm{~kg} / \mathrm{m}^{2}\right)$, overweight ( 25 to $<30 \mathrm{~kg}$ / $\mathrm{m}^{2}$ ) and obese $\left(\geq 30 \mathrm{~kg} / \mathrm{m}^{2}\right)$ ) and height ${ }^{3132}$ (below vs above the average height (men, $177 \mathrm{~cm}$; women, $164 \mathrm{~cm}$ )) and ethnicity ${ }^{16334}$ (white; other). In addition, as sexual behaviour and the number of potential sexual partners may vary by sexual identity, ${ }^{35}$ we also assessed this variable (heterosexual; other sexual identities). Categories were collapsed to maximise the statistical power available. 


\section{Statistical analyses}

All analyses were done using Stata V.15.0, accounting for stratification, clustering and weighting of the samples. ${ }^{90}$ These were performed separately by gender due to differences in the experience and reporting of sexual behaviours, ${ }^{9}$ and the 'sexual scripts' which shape these behaviours. ${ }^{36}$ First, we assessed the prevalence of sexual inactivity and each category of sexual inactivity for the population as a whole (aged 16-74 years) and by 5 year age groups. Next, among those who were sexually active as well as sexually inactive and in a relationship or single, we estimated the proportion who were dissatisfied with their sex life and the proportion who avoided sex due to sexual difficulties; for reasons of statistical power, these analyses were performed using two age groups: $16-44$ years and $45-74$ years. We used the $\chi^{2}$ test to assess differences in the proportion dissatisfied by sex, age group and type of sexual inactivity (single versus in a relationship). We then described the characteristics (the variables selected a priori as described above) of Natsal-3 participants who were sexually active and by each category of sexual inactivity. Although categories were collapsed to maximise the statistical power available, some subgroups were unavoidably small such that estimates for those with less than 50 observations are presented in square brackets to denote that these estimates should be considered with extra caution. Finally, we used logistic regression to calculate age-adjusted ORs to assess the association between each of the participant characteristics variables and each category of sexual inactivity as compared with being sexually active. Age-adjusted ORs with $95 \%$ CIs that did not overlap 1 were considered as statistically significant. Participants with missing data on the investigated variables were few (weighted proportion $<5 \%$ for all variables) and therefore excluded from analyses.

\section{Patient and public involvement}

As an unfunded secondary analysis of Natsal-3 data, this particular paper did not entail patient and public involvement. However, public engagement has been a key component of each phase of the Natsal study, including public consultation exercises to inform new topic areas, cognitive interviews to inform question wording and interactive public engagement events (including via digital media) to disseminate findings.

\section{RESULTS}

\section{Prevalence and categories of sexual inactivity}

The prevalence of sexual inactivity in the British resident population aged 16-74 years was estimated to be $15.9 \%$ (95\% CI, $15.0 \%$ to $17.0 \%$ ) for men and $22.2 \%$ (21.2\% to $23.3 \%$ ) for women (figure 1 and Online supplementary table 2). As well as there being a significantly larger proportion of women in the population who were sexually inactive relative to men $(\mathrm{p}<0.0001)$, gender differences also existed in terms of the context of this sexual inactivity $(\mathrm{p}<0.0001)$. Among sexually inactive men, $26.3 \%$
$(23.6 \%-29.3 \%)$ were sexually inexperienced, $33.2 \%$ $(29.9 \%$ to $36.8 \%)$ were in a relationship and $40.4 \%$ (37.2 to 43.7 ) were single. Among sexually inactive women, $16.3 \%$ ( $14.6 \%$ to $18.1 \%$ ) were sexually inexperienced, $33.9 \%$ (31.4 to 36.6 ) were in a relationship and $49.8 \%$ (47.2 to 52.4) were single.

The prevalence of sexual inactivity and types of sexual inactivity varied by age (figure 1 and online supplementary table 2). Among both men and women, the prevalence of sexual inactivity decreased with age from 16 to 19 years where $33.1 \%$ (29.6\% to $36.8 \%$ ) of men and $34.2 \%$ (30.9\% to $37.7 \%)$ of women were sexually inactive, reaching its lowest levels in the age groups between 35 and 39 years (men, $4.1 \%$ (2.5\% to $6.6 \%$ ); women, $6.4 \%$ $(4.4 \%$ to $9.3 \%))$ and then increased with age. The prevalence of sexual inactivity tended to be higher among women than men from age 40-44 years and older. In the oldest age group (70-74 years), the prevalence was $48.6 \%$ ( $42.3 \%$ to $55.0 \%)$ for men and $65.7 \%$ (59.9\% to $41.1 \%)$ for women.

Those sexually inexperienced comprised the majority of sexual inactivity in the youngest age group $(89.2 \%$ $(84.7 \%$ to $92.5 \%)$ of sexually inactive men and $95.1 \%$ $(92.0 \%$ to $97.0 \%)$ of sexually inactive women); a proportion that decreased with increasing age to $16.2 \%(7.2 \%$ to $32.6 \%$ ) of men and $15.0 \%$ ( $7.4 \%$ to $28.1 \%$ ) of women in the age-group 30-34 years. In the age range 30-59 years, sexually inactive singlehood comprised most of the sexual inactivity in both genders. The proportion of those who were sexually inactive who were in a relationship increased with age from ages of 40-44 years and older, although it decreased again among the oldest women. In the oldest age category, those in relationships comprised roughly two-thirds of sexually inactive men, and more than half of the sexually inactive women.

\section{Dissatisfaction with sexual inactivity and avoidance of sex due to sexual difficulties}

Overall, $34.8 \%(31.1 \%-38.7 \%)$ of men and $23.6 \%$ $(21.3 \%-26.1 \%)$ of women who were sexually inactive yet had previous sexual experience reported that they were dissatisfied with their sex lives $(p<0.001$ for gender difference; table 1). Among men (only), a slightly larger proportion of those who were single were dissatisfied than those in a relationship (37.8\% vs $31.1 \%$ ) but this did not reach statistical significance. In contrast, there was a strong association between age and dissatisfaction, with younger sexually inactive men and women more likely to report dissatisfaction. Similar age differences were observed when stratified by relationship status, although these were only statistically significant among those men and women who were single, reflecting the low prevalence of sexual inactivity among those aged 16-44 in relationships. Among those who were sexually active, $14.8 \%$ ( $13.7 \%$ to $16.0 \%)$ of women and $11.5 \%$ (10.6\% to $12.4 \%)$ of men reported that they were dissatisfied with their sex lives. 


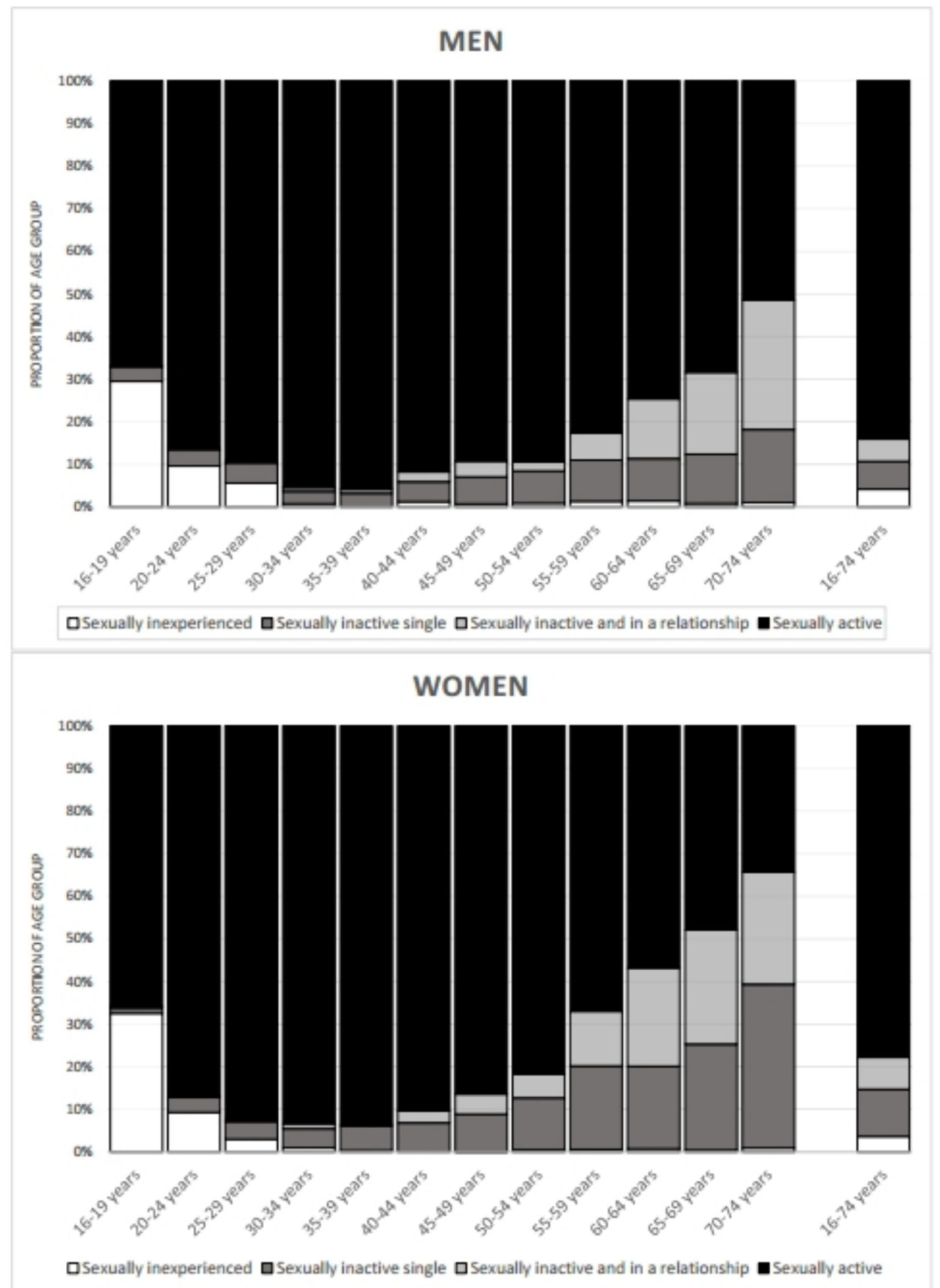

Figure 1 Percentage distribution of sexual (in)activity and types of sexual inactivity by age-group and gender.

Overall, $22.3 \%(19.1 \%$ to $25.8 \%)$ of men and $18.3 \%$ $(15.9 \%$ to $20.9 \%)$ of women who were sexually inactive yet had previous sexual experience reported that they had avoided sex because of their own or their partner's sexual difficulties (online supplementary table 3). The proportion who were sexually inactive and avoided sex because of sexual difficulties was larger for those who were in a relationship than those who were single in both age groups for women, but only among those aged 45-74 years for men.

\section{Variations in characteristics by sexual inactivity group}

The percentage distribution of individual-level characteristics of participants by type of sexual inactivity is shown in table 2 (men) and table 3 (women) and for those sexually active for reference. In the three categories of sexual inactivity, the numbers of men and women who reported they had never felt sexual attraction were too small to estimate proportions, with almost all reporting at least some sexual attraction at some point in their lives. The exception was sexually inexperienced women of which $11.0 \%$ $(7.7 \%$ to $15.6 \%)$ reported never having felt sexual attraction (to date).

\section{Factors associated with sexual inactivity}

Age-adjusted ORs for each type of sexual inactivity versus being sexually active for the sociodemographic and sexual behavioural/attitudinal characteristics, stratified 
Table 1 Variations in reporting dissatisfaction with sex life among sexually active or inactive men and women, by age-group, and whether in a relationship or not (those sexually inactive)

\begin{tabular}{|c|c|c|c|c|c|c|c|c|c|c|}
\hline & \multicolumn{5}{|l|}{ Men } & \multicolumn{5}{|l|}{ Women } \\
\hline & $\begin{array}{l}\text { Sexually } \\
\text { active } \\
\text { All }^{*}\end{array}$ & $A \|^{*}$ & $\begin{array}{l}\text { In a } \\
\text { relationship }\end{array}$ & Single & $\mathrm{P}$ value $†$ & All ${ }^{*}$ & All $^{*}$ & $\begin{array}{l}\text { In a } \\
\text { relationship }\end{array}$ & Single & $\mathrm{P}$ value \\
\hline & $\begin{array}{l}\%(95 \% \mathrm{Cl}) \\
{[\mathrm{N}] \dagger}\end{array}$ & $\begin{array}{l}\%(95 \% \\
\mathrm{Cl}) \\
{[\mathrm{N}] \dagger}\end{array}$ & $\begin{array}{l}\%(95 \% \mathrm{Cl}) \\
{[\mathrm{N}] \dagger}\end{array}$ & $\begin{array}{l}\%(95 \% \\
\mathrm{Cl})[\mathrm{N}] \dagger\end{array}$ & & $\begin{array}{l}\%(95 \% \mathrm{Cl}) \\
{[\mathrm{N}] \dagger}\end{array}$ & & $\begin{array}{l}\%(95 \% \mathrm{Cl}) \\
{[\mathrm{N}] \dagger}\end{array}$ & $\begin{array}{l}\%(95 \% \\
\mathrm{Cl}) \\
{[\mathrm{N}] \dagger}\end{array}$ & \\
\hline All & $\begin{array}{l}14.8 \% \\
(13.7 \% \text { to } \\
16.0 \%) \\
{[4813]}\end{array}$ & $\begin{array}{l}34.8 \% \\
(31.1 \% \text { to } \\
38.7 \%) \\
{[744]}\end{array}$ & $\begin{array}{l}31.1 \% \\
(25.4 \% \text { to } \\
37.6 \%) \\
{[232]}\end{array}$ & $\begin{array}{l}37.8 \% \\
(33.4 \% \text { to } \\
42.4 \%) \\
{[512]}\end{array}$ & 0.088 & $\begin{array}{l}11.5 \% \\
(10.6 \% \text { to } \\
12.4 \%) \\
{[6549]}\end{array}$ & $\begin{array}{l}23.6 \% \\
(21.3 \% \text { to } \\
26.1 \%) \\
{[1448]}\end{array}$ & $\begin{array}{l}23.2 \% \\
(19.2 \% \text { to } \\
27.8 \%) \\
{[424]}\end{array}$ & $\begin{array}{l}23.9 \% \\
(21.2 \% \text { to } \\
26.8 \%) \\
{[1024]}\end{array}$ & 0.794 \\
\hline \multicolumn{11}{|c|}{ By age-group } \\
\hline $45-74$ & $\begin{array}{l}15.6 \% \\
(13.6 \% \text { to } \\
17.7 \%) \\
{[1465]}\end{array}$ & $\begin{array}{l}32.2 \% \\
(28.0 \% \text { to } \\
36.7 \%) \\
{[542]}\end{array}$ & $\begin{array}{l}30.0 \% \\
(24.1 \% \text { to } \\
36.7 \%) \\
{[212]}\end{array}$ & $\begin{array}{l}34.6 \% \\
(29.2 \% \text { to } \\
40.4 \%) \\
{[330]}\end{array}$ & 0.283 & $\begin{array}{l}12.0 \% \\
(10.5 \% \text { to } \\
13.7 \%) \\
{[1660]}\end{array}$ & $\begin{array}{l}21.0 \% \\
(18.5 \% \text { to } \\
23.7 \%) \\
{[1128]}\end{array}$ & $\begin{array}{l}22.3 \% \\
(18.1 \% \text { to } \\
27.1 \%) \\
{[384]}\end{array}$ & $\begin{array}{l}19.9 \% \\
(16.9 \% \text { to } \\
23.1 \%) \\
{[744]}\end{array}$ & 0.384 \\
\hline $\mathrm{P}$ value§ & 0.333 & 0.006 & 0.256 & 0.048 & & 0.368 & $<0.001$ & 0.075 & $<0.001$ & \\
\hline
\end{tabular}

*These proportions have been previously presented $;{ }^{43}$ slight differences in the estimates are due to differences in inclusion/exclusion criteria for the study population.

$\dagger P$ value for difference by relationship status.

\#‘\% (95\% Cl) [N]' gives the denominator for the corresponding \% $(95 \% \mathrm{Cl})$.

$\S \mathrm{P}$ value for difference by age-group.

by gender, are shown in table 4; several significant associations were identified. For example, among both men and women, having a religion, in particular a non-Christian one (versus no religion), was significantly associated with a greater likelihood of sexual inexperience. A non-white ethnicity (versus white ethnicity) was associated with a greater likelihood of sexual inexperience among both men and women, and with sexually inactive singlehood among women. Conversely, among men, a non-white ethnicity was associated with a lower likelihood of being sexually inactive and single.

The socioeconomic profile of participants was associated with all three types of sexual inactivity in both genders. As compared with managerial and professional occupations, semiroutine or routine occupation, unemployment and being a full-time student were associated with sexually inactive singlehood and sexual inexperience among men. Similar associations were observed among women although semiroutine or routine occupation was not associated with sexual inexperience and those who were unemployed were also more likely to be sexually inactive and in a relationship. In both genders, the likelihood of being sexually inactive and single tended to increase with increasing quintile of Index of Multiple Deprivation.

Associations with body mass index differed by type of sexual inactivity and gender. Higher body mass index, in particular a value in the obese range $\left(\geq 30 \mathrm{~kg} / \mathrm{m}^{2}\right)$, tended to be associated with being sexually inactive while in a relationship (men and women) and sexually inactive single (women), whereas such associations were not observed for sexual inexperience. For both men and women, a body height below the population average, as compared with at the average or above, was associated with sexually inactive singlehood and sexual inexperience.

\section{DISCUSSION}

While the importance of sexual activity for quality of life has been increasingly recognised, ${ }^{1-3}$ this paper addresses how relatively little is known about those in the population who are sexually inactive. Specifically, we used nationally representative data from Britain to examine how the prevalence and type of sexual inactivity varies across the life course and assessed dissatisfaction with the (lack of) sex life and factors hypothesised to be related to reasons for sexual inactivity.

As previously reported, ${ }^{9}$ we found that around one in five men and women aged between 16 and 74 years were sexually inactive. The lowest prevalence of sexual inactivity was observed among those aged $35-39$ years (men: $4.1 \%$; women: $6.4 \%$ ). At ages of 30 years and older, the prevalence of sexual inactivity among women tended to be higher than among men, with the largest differences 
Table 2 Sociodemographic and sexual behaviour/attitudinal characteristics of British men by sexual (in)activity type (numbers are shown in per cent)

\section{Sexually active Sexually inactive}

\begin{tabular}{|c|c|c|c|c|}
\hline & & Sexually inexperienced & In a relationship & Single \\
\hline \multicolumn{5}{|l|}{ Age group } \\
\hline $16-24$ years & 15.4 & 71.6 & {$[[0.7]]$} & 9.4 \\
\hline 25-34 years & 20.4 & [14.3] & {$[[2.1]]$} & 11.1 \\
\hline $35-44$ years & 21.4 & [[3.0]] & {$[[6.0]]$} & 11.8 \\
\hline $45-54$ years & 20.0 & {$[[3.6]]$} & {$[[10.8]]$} & 20.0 \\
\hline $55-64$ years & 14.7 & {$[[5.2]]$} & 30.7 & 24.0 \\
\hline $65-74$ years & 8.1 & {$[[2.4]]$} & 49.7 & 23.8 \\
\hline \multicolumn{5}{|l|}{ Religion } \\
\hline None & 54.5 & 45.0 & 35.7 & 50.6 \\
\hline Christian & 38.7 & 31.8 & 59.5 & 42.3 \\
\hline Other religion & 6.9 & 23.2 & {$[[4.8]]$} & [7.1] \\
\hline \multicolumn{5}{|l|}{ Ethnicity } \\
\hline White/White British & 88.3 & 67.9 & 92.5 & 93.7 \\
\hline Other & 11.7 & 32.1 & {$[[7.5]]$} & (6.3) \\
\hline \multicolumn{5}{|l|}{ Education* } \\
\hline No academic qualification & 18.1 & 14.6 & 36.1 & 39.0 \\
\hline Academic qualifications typically gained at age $16 \mathrm{y}$ & 34.4 & 11.6 & 27.8 & 24.3 \\
\hline Studying for/attained further academic qualification & 47.5 & 73.8 & 36.2 & 36.8 \\
\hline \multicolumn{5}{|l|}{ National Statistics Socio-Economic Classification } \\
\hline Managerial \& professional occupations & 38.0 & [[7.2]] & 31.5 & 26.0 \\
\hline Intermediate occupations & 17.6 & {$[[5.6]]$} & 16.5 & 12.1 \\
\hline Semiroutine/routine occupations & 32.8 & [14.8] & 32.6 & 36.1 \\
\hline Never worked and long-term unemployed & 4.5 & [11.8] & [18.5] & 21.4 \\
\hline Student in full-time education & 7.2 & 60.6 & {$[[0.9]]$} & [[4.6]] \\
\hline \multicolumn{5}{|l|}{ Quintile of Index of Multiple Deprivation } \\
\hline 1 (least deprived) & 20.8 & 15.9 & 25.9 & 13.9 \\
\hline 2 & 21.3 & 18.0 & 29.7 & 16.7 \\
\hline 3 & 19.6 & 17.0 & [18.4] & 20.1 \\
\hline 4 & 20.1 & 24.7 & {$[15.1]$} & 22.3 \\
\hline 5 (most deprived) & 18.2 & 24.4 & {$[[10.9]]$} & 27.1 \\
\hline \multicolumn{5}{|l|}{ Body mass index $\left(\mathrm{kg} / \mathrm{m}^{2}\right)$} \\
\hline$<25$ (underweight or normal weight) & 41.8 & 71.2 & 24.5 & 42.2 \\
\hline 25 to $<30$ (overweight) & 39.6 & 17.9 & 43.8 & 35.0 \\
\hline 30 or higher (obese) & 18.6 & [10.9] & 31.8 & 22.8 \\
\hline \multicolumn{5}{|l|}{ Height } \\
\hline Below average $(<177 \mathrm{~cm})$ & 41.2 & 44.9 & 53.8 & 50.3 \\
\hline Average or above $(\geq 177 \mathrm{~cm})$ & 58.8 & 55.1 & 46.2 & 49.7 \\
\hline \multicolumn{5}{|l|}{ Have felt sexual attraction } \\
\hline Yes & 99.9 & 92.7 & 99.6 & 99.8 \\
\hline No & {$[[0.1]]$} & {$[[7.3]]$} & {$[[0.4]]$} & {$[[0.2]]$} \\
\hline \multicolumn{5}{|l|}{ Sexual identity } \\
\hline Heterosexual & 97.3 & 95.3 & 99.1 & 95.3 \\
\hline Other & 2.7 & {$[[4.7]]$} & {$[[0.9]]$} & {$[[4.7]]$} \\
\hline
\end{tabular}


Table 2 Continued

\section{Sexually active Sexually inactive}

\begin{tabular}{|c|c|c|c|c|}
\hline \multicolumn{5}{|c|}{ Masturbated in past 7 days } \\
\hline Yes & 49.4 & 49.1 & 25.3 & 43.9 \\
\hline 0 & 0 & 100 & {$[[0.3]]$} & 0 \\
\hline 1 & 12.9 & 0 & 24.1 & 15.5 \\
\hline 5 or more & 64.1 & 0 & 47.8 & 51.4 \\
\hline \multicolumn{5}{|l|}{ Ever paid for sex } \\
\hline No & 89.0 & 100 & 88.8 & 85.9 \\
\hline Yes & 11.0 & 0 & [[11.2]] & 14.1 \\
\hline
\end{tabular}

[ ] Small numerator (between 30 and 50 participants).

[[ ]] Small numerator (<30 participants).

${ }^{*}$ Not defined when asked in interview.

†All participants (denominators vary across variables because of item non-response).

in the oldest ages: among those aged 70-74 years, prevalence was $48.6 \%$ for men vs $65.7 \%$ for women. These findings may partly be explained by the higher likelihood of women to be living without a partner due to divorce or widowhood and subsequently having no new partner $^{37-40}$ and by the upper age limit of 74 years in the Natsal survey, as men tend to be older than their female partners ${ }^{41}$ and the likelihood of sexual inactivity increases with age. Other explanations include those related to gender differences in sampling (eg, the ineligibility of non-UK-resident sexual partners in Natsal-3 or potential underrepresentation of sex workers ${ }^{42}$ ) and gender differences in accounting of sexual partners, although conformity to gendered norms and reporting bias may also have affected the results. ${ }^{42}$

While those sexually inexperienced comprised the majority of those who were sexually inactive in young adulthood, sexually inactive singlehood was the major type of sexual inactivity from then on until the late $50 \mathrm{~s}$. In older age-groups, the proportion of the sexually inactive who were in a relationship overtook the proportion who were sexually inactive and single, especially among men.

Although positive sexual experiences are important contributors to quality of life, ${ }^{1346}$ some individuals may not consider the absence of sex as a source of dissatisfaction or may choose to be sexually inactive. Importantly, among those who had previous sexual experience but were sexually inactive in our study, around one in three men and one in four women reported that they were dissatisfied with their sex life. Dissatisfaction with sex life among those who were sexually inactive tended to be lower in those aged 45-74 years as compared with 16-44 years. These analyses, which did not include those who were sexually inexperienced as the question about satisfaction with sex life was only asked to those who reported previous sexual experience, are in line with previous analyses of Natsal- $3 .^{43}$ Moreover, in a US study, individuals who were sexually inactive reported similar happiness levels as their sexually active counterparts. ${ }^{16}$ While involuntary sexual inactivity is a source of dissatisfaction for some individuals ${ }^{12}$ and the proportion dissatisfied was larger among sexually inactive Natsal participants (not including those without sexual experience) as compared with those who were sexually active, these data underscore that a substantial proportion of those who are sexually inactive, especially in older age groups, may not consider their lack of sexual activity as a problem. Indeed, the proportion of men and women reporting a lack of interest in sex increased with age. ${ }^{15} \mathrm{~A}$ further explanation is that individuals may adjust their priorities, type of sexual activity and expectations to cope with their own health challenges, and those of their partners, ${ }^{445}$ which are likely to be more prevalent at older ages. ${ }^{46}$

The mechanisms leading to an individual being sexually inactive are multifactorial and likely to operate in more than one direction. What constitutes involuntary sexual inactivity is not clear as individuals' selectiveness when choosing with whom to have sex and the level of effort that they are willing to put in for attracting and pursuing sexual partners probably affects the likelihood of being sexually inactive. Acknowledging these limitations, we assessed factors that may reflect reasons for sexual inactivity. While asexuality, that is, the absence of sexual attraction to others, has received increased 
Table 3 Sociodemographic and sexual behaviour/attitudinal characteristics of British women by sexual (in)activity type (numbers are shown in per cent)

\section{Sexually active Sexually inactive}

\begin{tabular}{|c|c|c|c|c|}
\hline & & Sexually inexperienced & In a relationship & Single \\
\hline \multicolumn{5}{|l|}{ Age group } \\
\hline 16-24 years & 15.8 & 82.7 & {$[[0.6]]$} & {$[3.8]$} \\
\hline 25-34 years & 21.8 & {$[10.2]$} & {$[[1.8]]$} & 7.1 \\
\hline $35-44$ years & 22.5 & {$[[0.9]]$} & {$[[4.1]]$} & 10.9 \\
\hline $45-54$ years & 20.5 & {$[[1.3]]$} & {$[12.8]$} & 17.7 \\
\hline $55-64$ years & 12.9 & [[3.0]] & 38.6 & 28.5 \\
\hline $65-74$ years & 6.5 & {$[[2.0]]$} & 42.1 & 32.1 \\
\hline \multicolumn{5}{|l|}{ Religion } \\
\hline None & 45.7 & 35.5 & 33.9 & 36.5 \\
\hline Christian & 48.5 & 36.9 & 62.2 & 58.2 \\
\hline Other religion & 5.8 & 27.6 & {$[[3.9]]$} & {$[5.4]$} \\
\hline \multicolumn{5}{|l|}{ Ethnicity } \\
\hline White British/White & 89.0 & 61.7 & 94.9 & 87.8 \\
\hline Other & 11.0 & 38.3 & {$[[5.1]]$} & 12.2 \\
\hline \multicolumn{5}{|l|}{ Education* } \\
\hline No academic qualification & 16.8 & {$[[5.8]]$} & 40.6 & 35.8 \\
\hline Academic qualifications typically gained at age $16 \mathrm{y}$ & 36.2 & {$[[8.1]]$} & 28.9 & 34.5 \\
\hline Studying for/attained further academic qualification & 47.0 & 86.0 & 30.5 & 29.6 \\
\hline \multicolumn{5}{|l|}{ National Statistics Socio-Economic Classification } \\
\hline Managerial \& professional occupations & 33.5 & [7.9] & 23.8 & 23.7 \\
\hline Intermediate occupations & 20.8 & {$[[4.0]]$} & 17.7 & 18.1 \\
\hline Semiroutine/routine occupations & 27.2 & [10.0] & 22.0 & 28.0 \\
\hline Never worked and long-term unemployed & 11.3 & [10.0] & 36.0 & 27.6 \\
\hline Student in full-time education & 7.3 & 68.1 & {$[[0.5]]$} & [2.6] \\
\hline \multicolumn{5}{|l|}{ Quintile of Index of Multiple Deprivation } \\
\hline 1 (least deprived) & 20.9 & 15.3 & 23.9 & 13.7 \\
\hline 2 & 20.7 & 13.2 & 24.1 & 18.4 \\
\hline 3 & 19.7 & 24.5 & 18.2 & 20.0 \\
\hline 4 & 19.9 & 24.2 & 16.5 & 24.0 \\
\hline 5 (most deprived) & 18.7 & 22.8 & 17.4 & 23.9 \\
\hline \multicolumn{5}{|l|}{ Body mass index $\left(\mathrm{kg} / \mathrm{m}^{2}\right)$} \\
\hline$<25$ (underweight or normal weight) & 54.0 & 74.1 & 35.1 & 39.5 \\
\hline 25 to $<30$ (overweight) & 28.0 & {$[13.8]$} & 35.7 & 30.0 \\
\hline 30 or higher (obese) & 18.1 & {$[12.1]$} & 29.1 & 30.5 \\
\hline \multicolumn{5}{|l|}{ Height } \\
\hline Below average $(<164 \mathrm{~cm})$ & 51.3 & 56.7 & 63.9 & 62.4 \\
\hline Average or above ( $\geq 164 \mathrm{~cm})$ & 48.8 & 43.3 & 36.1 & 37.6 \\
\hline \multicolumn{5}{|l|}{ Have felt sexual attraction } \\
\hline Yes & 99.8 & 89.0 & 99.7 & 98.8 \\
\hline No & {$[[0.2]]$} & [11.0] & {$[[0.3]]$} & [[1.2]] \\
\hline \multicolumn{5}{|l|}{ Sexual identity } \\
\hline Heterosexual & 97.3 & 96.7 & 96.8 & 97.8 \\
\hline Other & 2.7 & {$[[3.3]]$} & {$[[3.2]]$} & {$[2.2]$} \\
\hline
\end{tabular}


Table 3 Continued

\section{Sexually active Sexually inactive}

\begin{tabular}{|c|c|c|c|c|}
\hline \multicolumn{5}{|c|}{ Masturbated in past 7 days } \\
\hline No & 82.0 & 90.2 & 94.8 & 90.2 \\
\hline Yes & 18.0 & {$[[9.8]]$} & {$[[5.2]]$} & 9.8 \\
\hline 0 & 0 & 100 & 0.2 & 0 \\
\hline 1 & 20.7 & 0 & 41.8 & 24.8 \\
\hline 5 or more & 49.1 & 0 & 26.1 & 38.9 \\
\hline \multicolumn{5}{|l|}{ Ever paid for sex } \\
\hline No & 99.9 & 100 & 99.4 & 99.9 \\
\hline Yes & {$[[0.1]]$} & 0 & {$[[0.6]]$} & {$[[0.1]]$} \\
\hline \multicolumn{5}{|l|}{ Denominators $†$} \\
\hline
\end{tabular}

[ ] Small numerator (between 30 and 50 participants).

[[ ]] Small numerator (<30 participants).

${ }^{*}$ Not defined when asked in interview.

†All participants (denominators vary across variables because of item non-response).

attention, ${ }^{14} 47$ only a very small proportion of those who were sexually inactive in our study reported that they had never felt sexual attraction to anyone, in line with previous population estimates of asexuality. ${ }^{14}$ Around a fifth of sexually inactive men and women (not including those without sexual experience) reported having avoided sex due to their own or their partner's sexual difficulties. This proportion tended to be higher among older men and women who were sexually inactive while in a relationship. Among sexually inactive singles, however, the proportion was only around 1 in 10 , indicating that sexual difficulties are not a major reason for sexual inactivity in this group. Having a religion was associated with a higher likelihood of sexual inexperience, but not with other types of sexual inactivity. Many individuals with an active faith may choose to remain sexually inactive until marriage. Other factors potentially reflected reasons for sexual inactivity that had far less to do with choice, for example, sexual function issues ${ }^{43}$ or difficulties in finding sexual partners. ${ }^{12}$ Among men and women, a body mass index in the obese range was associated with being sexually inactive yet in a relationship and with sexually inactive singlehood (women). Moreover, our study showed an association with height, in that those men and women who were sexually inexperienced or sexually inactive singles were more likely to be shorter than average. Body shape for $\operatorname{men}^{30}$ and women ${ }^{28} 29$ has been shown to be determinants of sexual attractiveness. Height has been established as a determinant for sexual attractiveness and reproductive success for men, ${ }^{31} 32$ and in some studies also for women. ${ }^{32}$ However, body shape and stature may also reflect overall health status that may be associated with poorer sexual function. ${ }^{48}$ Routine occupations (men only), unemployment and being a student were associated with sexual inexperience and sexually inactive singlehood in both genders. These findings are in line with a study from the USA showing an association between low household income as well as low contribution to the household income and increased likelihood of sexual inactivity in the past year in both genders. ${ }^{16}$ Studies have shown that high 2223 and stable ${ }^{22}$ incomes constitute important partner preferences, especially when men are evaluated as potential romantic partners. ${ }^{25} 49$ However, previous analyses of Natsal-3 data showed that unemployed men, but not women, were more likely to report a lack of interest in sex, ${ }^{15}$ and that unemployment was associated with more sexual function issues in both genders, ${ }^{43}$ indicating that low income or occupational status and sexual inactivity may share common determinants.

Previous population-based studies on sexual inactivity have included only young adults, ${ }^{10} 111719$ assessed only one type of sexual inactivity (eg, sexual inexperience or sexually inactive relationships) ${ }^{10-19}$ or analysed sexually inactive individuals as one group. ${ }^{9}{ }^{16}$ In our study, we included men and women across a wide age-range, corresponding to most of adulthood, using nationally representative data from Britain. To our knowledge, this is also the first study to assess prevalence of, and factors associated with, different types of sexual inactivity.

Our study has limitations. First, as our analyses relied on self-reported data, the findings might have been affected by under-reporting or over-reporting of sexual inactivity due to social desirability bias. ${ }^{50}$ Second, although the response rate in Natsal-3 was in line with other major 


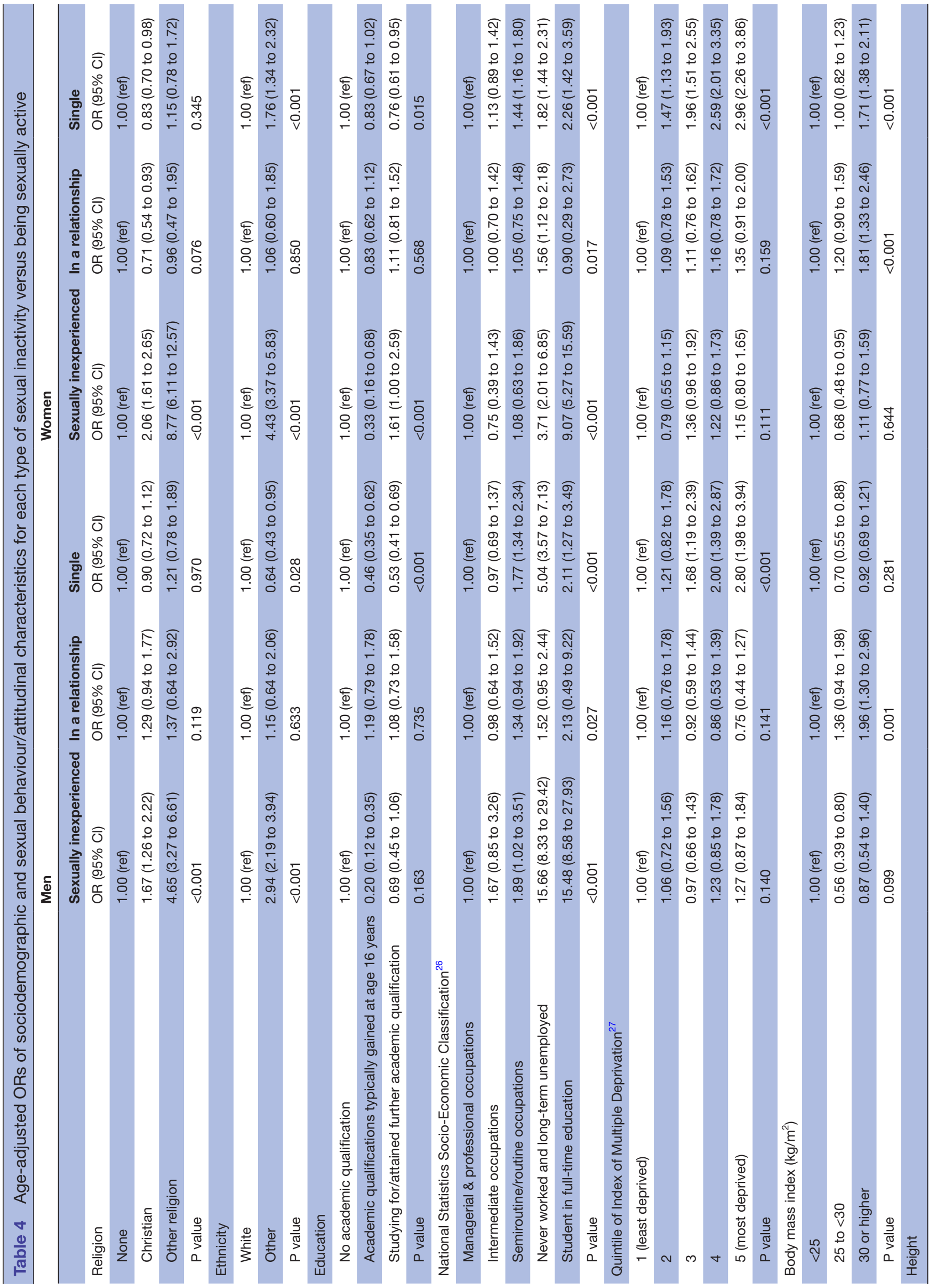




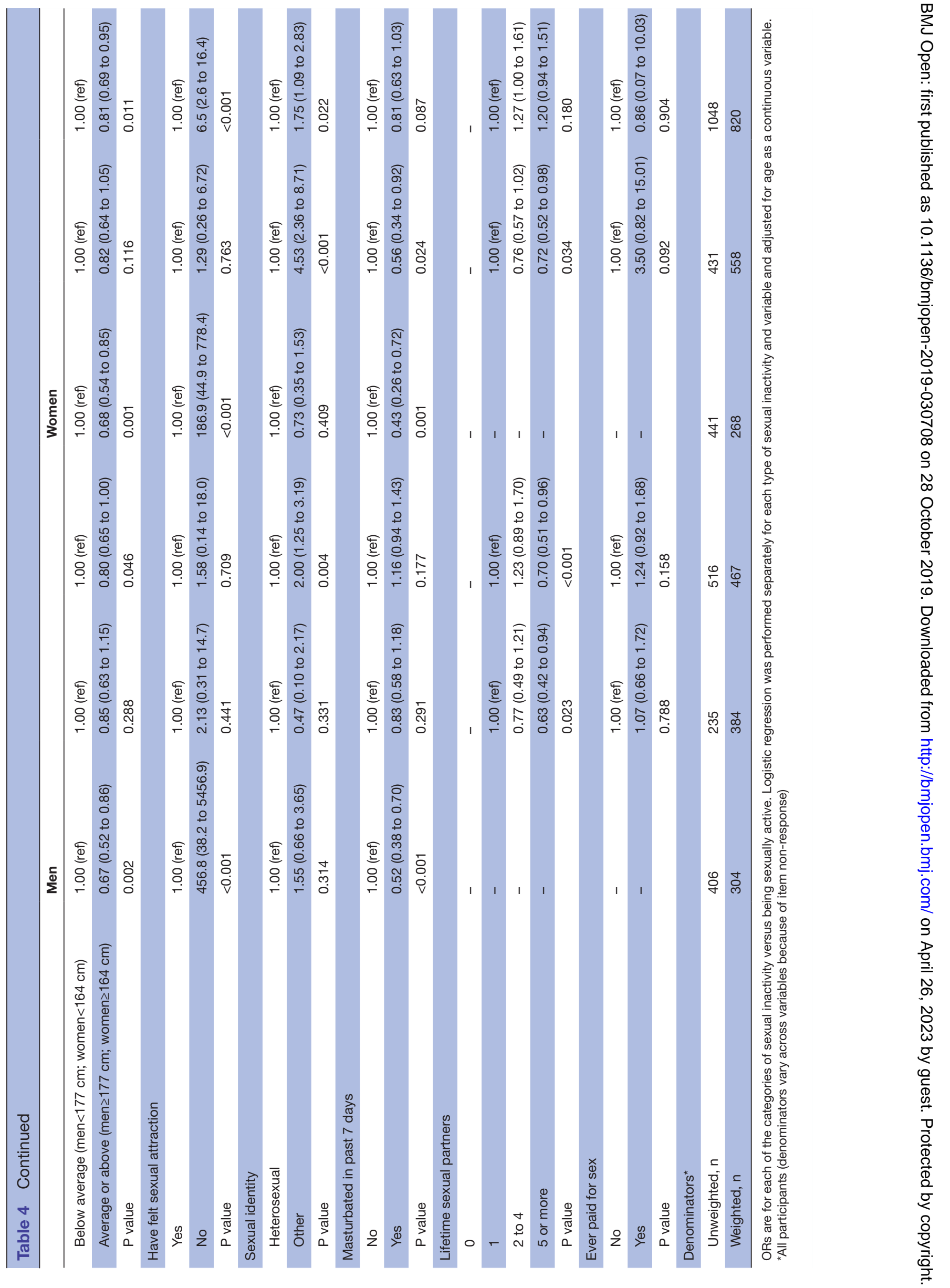


social surveys in Britain ${ }^{51} 52$ and the sample was weighted to be broadly representative of the underlying British population with respect to the distribution of gender, age and regions as used in the census, non-response could be a source of bias for our data especially as the sexually inactive may have been less likely to participate although the invitation to do so emphasised the importance of everyone's participation regardless of sexual experience. Third, as the question on satisfaction with sex life was not asked to those with no previous sexual experience, we could not assess the potential dissatisfaction with the absence of sex among the sexually inexperienced. Fourth, we defined sexual activity based on physical interactions between individuals, which we limited to specifically vaginal, oral and anal sexual intercourse. However, we recognise that for some, non-penetrative sexual activities, for example, mutual masturbation, may be regarded as sexual activity regardless of whether or not it is considered as fulfilling as intercourse. Engaging in such sexual activities may be more common where an individual and/or their partner has physical disabilities that prevent intercourse, which as these are likely to be more prevalent in older age ${ }^{46}$ may mean that we overestimated sexual inactivity in these age-groups, particularly sexual inactivity among those in relationships. In addition, some individuals may consider other types of activities such as cyber-sex and sexual fantasies as sexual activities that enable them to have what they consider to be a satisfying sex life, which we were not able to take account of in our study as Natsal-3 did not ask about these activities. Fifth, due to the cross-sectional design, temporality of the associations between participant characteristics and sexual inactivity could not be determined. Sixth, as our analyses were limited to information available in Natsal-3, some factors of potential importance, such as health conditions impairing sexual desire and availability of private space in multiperson households, were not investigated. Previous studies have assessed factors associated with the broader issue of sexual activity, including as outcomes: lacking interest in sex ${ }^{15}$ low sexual function ${ }^{43}$ as well as the role of household structure on sexual behaviour, ${ }^{52}$ and the association between general health and well-being and sexual activity. ${ }^{46}$ Finally, in some of our analyses on subgroups of the sexually inactive population, sample size was limited and detailed analyses of participant characteristics was therefore not possible to perform.

Our findings have implications for research and practice. Taken together, our study demonstrates the range of sexual inactivity that exists throughout the life course, and the need to take account for types of sexual inactivity in future studies on the topic. Although sex is widely recognised as important for well-being and some individuals may experience distress due to difficulties in pursuing a fulfilling sex life, many of the sexually inactive individuals, including those in relationships, may not perceive their sexual inactivity as problematic. Our findings should be recognised by health professionals as well as in sex and relationship education and counselling.
In addition, further research is needed to investigate the mechanisms and context for being sexually inactive for those for whom this causes distress.

Acknowledgements The authors thank Professor Kirstin Mitchell for her helpful comments when drafting the paper.

Contributors PU and CHM formulated the research questions and the study design. PU wrote the first draft of the paper with further contributions from CHM. PU performed statistical analyses. Both authors contributed to data interpretation and approved the final version of the manuscript.

Funding Natsal-3 was supported by grants from the U.K. Medical Research Council (G0701757) and the Wellcome Trust (084840), with support from the Economic and Social Research Council and the Department of Health. However, no funding was received to undertake this paper as secondary analyses of the Natsal-3 data.

Competing interests None declared.

Patient consent for publication Not required.

Ethics approval Natsal-3 was approved by the NRES Committee South CentralOxford A (Ref: 10/H0604/27). Participants provided oral informed consent for interviews.

Provenance and peer review Not commissioned; externally peer reviewed.

Data availability statement The Natsal-3 data set is publicly available from the UK Data Service: https://discover.ukdataservice.ac.uk/; SN: 7799; persistent identifier: 10.5255/UKDA-SN-77991-1.

Open access This is an open access article distributed in accordance with the Creative Commons Attribution Non Commercial (CC BY-NC 4.0) license, which permits others to distribute, remix, adapt, build upon this work non-commercially, and license their derivative works on different terms, provided the original work is properly cited, appropriate credit is given, any changes made indicated, and the use is non-commercial. See: http://creativecommons.org/licenses/by-nc/4.0/.

ORCID iD

Peter Ueda http://orcid.org/0000-0002-3275-8743

\section{REFERENCES}

1 World Health Organization. Defining Sexual Health - Report of technical consultation on sexual health 28-31 January 2002, Geneva., 2006. Available: http://www.who.int/reproductivehealth/ publications/sexual_health/defining_sexual_health.pdf

2 Wellings K, Johnson AM. Framing sexual health research: adopting a broader perspective. The Lancet 2013;382:1759-62.

3 Starrs AM, Ezeh AC, Barker G, et al. Accelerate progress-sexual and reproductive health and rights for all: report of the GuttmacherLancet Commission. The Lancet 2018;391:2642-92.

4 Kahneman D, Krueger AB, Schkade D, et al. Toward national wellbeing accounts. American Economic Review 2004;94:429-34.

5 Blanchflower DG, Oswald AJ, Money OAJ. Money, sex and happiness: an empirical study. Scand J Econ 2004;106:393-415.

6 Schmiedeberg C, Huyer-May B, Castiglioni L, et al. The more or the better? how sex contributes to life satisfaction. Arch Sex Behav 2017;46:465-73.

7 Lindau ST, Gavrilova N, Sex GN. Sex, health, and years of sexually active life gained due to good health: evidence from two US population based cross sectional surveys of ageing. BMJ 2010;340:c810.

8 Smith GD, Frankel S, Yarnell J. Sex and death: are they related? findings from the Caerphilly cohort study. BMJ 1997;315:1641-4.

9 Mercer $\mathrm{CH}$, Tanton C, Prah P, et al. Changes in sexual attitudes and lifestyles in Britain through the life course and over time: findings from the National surveys of sexual attitudes and lifestyles (Natsal). The Lancet 2013;382:1781-94.

10 Twenge JM, Sherman RA, Wells BE. Sexual inactivity during young adulthood is more common among U.S. Millennials and iGen: age, period, and cohort effects on having no sexual partners after age 18. Arch Sex Behav 2017;46:433-40.

11 Beutel ME, Burghardt J, Tibubos AN, et al. Declining sexual activity and desire in men-findings from representative German surveys, 2005 and 2016. J Sex Med 2018;15:750-6.

12 Donnelly D, Burgess E, Anderson S, et al. Involuntary celibacy: a life course analysis. J Sex Res 2001;38:159-69. 
13 Donnelly DA, Burgess EO. The decision to remain in an Involuntarily Celibate relationship. J Marriage and Family 2008;70:519-35.

14 Aicken $\mathrm{CRH}$, Mercer $\mathrm{CH}$, Cassell JA. Who reports absence of sexual attraction in Britain? Evidence from national probability surveys. Psychology and Sexuality 2013;4:121-35.

15 Graham CA, Mercer CH, Tanton C, et al. What factors are associated with reporting lacking interest in sex and how do these vary by gender? findings from the third British national survey of sexual attitudes and lifestyles. BMJ Open 2017;7:e016942.

$16 \mathrm{Kim} \mathrm{JH}$, Tam WS, Muennig P. Sociodemographic correlates of Sexlessness among American adults and associations with selfreported Happiness levels: evidence from the U.S. General social survey. Arch Sex Behav 2017;46:2403-15.

17 Haydon AA, Cheng MM, Herring AH, et al. Prevalence and predictors of sexual inexperience in adulthood. Arch Sex Behav 2014;43:221-30.

18 Kim JH, Lau Joseph Tak-Fai, Cheuk Ka-Kin. Sexlessness among married Chinese adults in Hong Kong: prevalence and associated factors. J Sex Med 2009;6:2997-3007.

19 Ghaznavi C, Sakamoto H, Yoneoka D, et al. Trends in heterosexual inexperience among young adults in Japan: analysis of national surveys, 1987-2015. BMC Public Health 2019;19:355.

20 Erens B, Phelps A, Clifton S, et al. Methodology of the third British national survey of sexual attitudes and lifestyles (Natsal-3). Sex Transm Infect 2014;90:84-9.

21 The American Association for Public Opinion Research.. Standard definitions: final dispositions of case codes and outcome rates for surveys. 7th edition, 2011AAPOR.

22 Fales MR, Frederick DA, Garcia JR, et al. Mating markets and bargaining hands: mate preferences for attractiveness and resources in two national U.S. studies. Pers Individ Dif 2016;88:78-87.

23 Hitsch GJ, Hortaçsu A, Ariely D. What makes you click? -Mate preferences in online dating. Quant Mark Econ 2010;8:393-427.

24 National Institute of Population and Social Security Research. The fifteenth Japanese national fertility survey in 2015. marriage process and fertility of married couples attitudes toward marriage and family among Japanese singles. summary of the survey results on married Couples/Singles, 2017.

25 Buunk BP, Dijkstra P, Fetchenhauer D, et al. Age and gender differences in mate selection criteria for various involvement levels. Pers Relatsh 2002;9:271-8.

26 Office for National Statistics. Standard occupational classification 2010: volumes 1-3, 2010.

27 Payne R, Abel G. UK indices of multiple deprivation - a way to make comparisons across constituent countries easier. In: Health statistics quarterly / Office for National Statistics, 2012.

28 Kościński K. Assessment of Waist-to-Hip ratio attractiveness in women: an anthropometric analysis of digital Silhouettes. Arch Sex Behav 2014;43:989-97.

29 Tovée MJ, Reinhardt S, Emery JL, et al. Optimum body-mass index and maximum sexual attractiveness. The Lancet 1998;352.

30 Maisey DS, Vale ELE, Cornelissen PL, et al. Characteristics of male attractiveness for women. Lancet 1999;353:1500.

31 Pawlowski B, Dunbar RI, Lipowicz A. Tall men have more reproductive success. Nature 2000;403:156.
32 Courtiol A, Raymond M, Godelle B, et al. Mate choice and human stature: Homogamy as a unified framework for understanding mating preferences. Evolution 2010;104:2189-203.

33 Bruch EE, Newman MEJ. Aspirational pursuit of mates in online dating markets. Sci. Adv. 2018;4:eaap9815.

34 Rudder C. Dataclysm: Who we are (when we think no one's looking. New York: Random House, 2014.

35 Glick SN, Morris M, Foxman B, et al. A comparison of sexual behavior patterns among men who have sex with men and heterosexual men and women. JAIDS Journal of Acquired Immune Deficiency Syndromes 2012;60:83-90.

36 Wiederman MW. The gendered nature of sexual Scripts. The Family Journal 2005;13:496-502.

37 Office for National Statistics. Families and households: 2012, 2012.

38 Office for National Statistics. 2011 census, 2011.

39 General Register Office for Scotland. 2011 census, 2011. Available: http://webarchive.nationalarchives.gov.uk/20121205080406/http:// www.gro-scotland.gov.uk/census/censushm2011/index.html [Accessed 26 Sep 2018].

40 Wilson B, Smallwood S. Age differences at marriage and divorce. Popul Trends 2008:17-25.

41 Mitchell KR, Mercer CH, Prah P, et al. Why do men report more opposite-sex sexual partners than women? analysis of the gender discrepancy in a British National probability survey. $J$ Sex Res 2018:1-8.

42 Mitchell KR, Mercer CH, Ploubidis GB, et al. Sexual function in Britain: findings from the third national survey of sexual attitudes and lifestyles (Natsal-3). The Lancet 2013;382:1817-29.

43 Gott M, Hinchliff S. How important is sex in later life? the views of older people. Soc Sci Med 2003;56:1617-28.

44 Holdsworth E, Trifonova V, Tanton C, et al. Sexual behaviours and sexual health outcomes among young adults with limiting disabilities: findings from third British national survey of sexual attitudes and lifestyles (Natsal-3). BMJ Open 2018;8:e019219.

45 Field N, Mercer CH, Sonnenberg P, et al. Associations between health and sexual lifestyles in Britain: findings from the third national survey of sexual attitudes and lifestyles (Natsal-3). The Lancet 2013;382:1830-44

46 Bogaert AF. Asexuality: what it is and why it matters. The Journal of Sex Research 2015;52:362-79.

47 Rowland DL, McNabney SM, Mann AR. Sexual function, obesity, and weight loss in men and women. Sexual Medicine Reviews 2017;5:323-38

48 Eastwick PW, Luchies LB, Finkel EJ, et al. The predictive validity of ideal partner preferences: a review and meta-analysis. Psychol Bull 2014;140:623-65.

49 Fenton KA. Measuring sexual behaviour: methodological challenges in survey research. Sex Transm Infect 2001;77:84-92.

50 Park A, Clery E, Curtice J, et al. British social attitudes 2012;28.

51 Mindell J, Biddulph JP, Hirani V, et al. Cohort profile: the health survey for England. Int J Epidemiol 2012;41:1585-93.

52 Curtis TJ, Field N, Clifton S, et al. Household structure and its association with sexual risk behaviours and sexual health outcomes: evidence from a British probability sample survey. BMJ Open 2018;8:24255. 